\title{
In reply to "could acupuncture be a treatment option for cancer patients with attitudinal barriers to pharmacological pain management?" by Kako, Kajiwara, and Kobayashi
}

\author{
Kevin T. Liou ${ }^{1}$ (D) - Jun J. Mao ${ }^{1}$ \\ Received: 8 October 2020 / Accepted: 19 October 2020 / Published online: 28 October 2020 \\ (C) Springer-Verlag GmbH Germany, part of Springer Nature 2020
}

We appreciate the correspondence regarding our article [1]. Kako et al. commented that patients' experiences with acupuncture are important factors to consider in our study on pain management preferences. We did not assess patients' prior use or experiences with acupuncture. However, our study used a validated instrument to evaluate patients' attitudes and beliefs about acupuncture, including their expectations about benefits; these factors are often shaped by patients' prior experiences with acupuncture [2,3]. We adjusted for these attitudes and beliefs in our analyses, and we still found a significant association between acupuncture preference and fear of analgesic side effects. These results suggest that patients' attitudes and beliefs about acupuncture are not the only factors influencing acupuncture preference.

Kako et al. also raised questions regarding the categorization of pain medications. Our pain medication classification was based on three main categories: opioid analgesics, nonopioid analgesics, and adjuvant medications. These categorizations are widely used in cancer pain management guidelines [4]. We also classified nonopioid analgesics and adjuvant medications into more detailed categories, e.g., acetaminophen, NSAIDs, anti-depressants, nerve pain pills, or muscle relaxants. In our analyses, the type of pain medication used was not significantly associated with acupuncture preference after adjusting for covariates. Other pain medication classifications can be explored in future research.

Finally, we would like to clarify that our article does not conclude acupuncture is the sole treatment option preferred by cancer patients who fear analgesic side effects. We examined

Kevin T. Liou

liouk@mskcc.org

1 Integrative Medicine Service, Department of Medicine, Memorial Sloan Kettering Cancer Center, 1429 First Avenue, New York, NY 10021, USA whether patients preferred acupuncture or pain medications; however, various other treatment modalities exist. Patients' attitudes and preferences towards these other options should be examined in future studies. As stated in our paper, "The evidence-based integration of acupuncture, medications, and other modalities, guided by careful consideration of patient treatment preferences, represents an essential aspect of patient-centered cancer pain management" [1]. We hope our study findings shed light on potential barriers to pain management and encourage providers to consider evidence-based treatment options that are aligned with patients' preferences. We believe this patient-centered approach is critical to address the problem of under-treated pain in the cancer population.

\section{References}

1. Liou KT, Trevino KM, Meghani SH, Li QS, Deng G, Korenstein D, Mao JJ (2020) Fear of analgesic side effects predicts preference for acupuncture: a cross-sectional study of cancer patients with pain in the USA. Support Care Cancer. https://doi.org/10.1007/s00520-020-05504-y

2. Bauml JM, Chokshi S, Schapira MM, Im EO, Li SQ, Langer CJ, Ibrahim SA, Mao JJ (2015) Do attitudes and beliefs regarding complementary and alternative medicine impact its use among patients with cancer? A cross-sectional survey. Cancer 121:2431-2438

3. Mao JJ, Palmer SC, Desai K, Li SQ, Armstrong K, Xie SX (2012) Development and validation of an instrument for measuring attitudes and beliefs about complementary and alternative medicine (CAM) use among cancer patients. Evid Based Complement Alternat Med. https://doi.org/10.1155/2012/798098

4. Swarm RA, Paice JA, Anghelescu DL, Are M, Bruce JY, Buga S, Chwistek M, Cleeland C, Craig D, Gafford E, Greenlee H, Hansen E, Kamal AH, Kamdar MM, LeGrand S, Mackey S, McDowell MR, Moryl N, Nabell LM, Nesbit S, O'Connor N, Rabow MW, Rickerson E, Shatsky R, Sindt J, Urba SG, Youngwerth JM, Hammond LJ, Gurski LA (2019) Adult Cancer Pain, Version 3.2019, NCCN Clinical Practice Guidelines in Oncology. J Natl Compr Canc Netw 17(8):977-1007.

Publisher's note Springer Nature remains neutral with regard to jurisdictional claims in published maps and institutional affiliations. 